\title{
Investigating the micro silica effect on the concrete strength
}

\author{
Stanislav Maslennikov ${ }^{1, *}$, Vladimir Dmitrienko ${ }^{1}$, Irina Kokunko ${ }^{1}$, and Nadezhda \\ Dmitrienko $^{1}$ \\ ${ }^{1}$ Don State Technical University, pl. Gagarina, 1, Rostov-on-Don, 344010, Russia
}

\begin{abstract}
The analysis of the impact of various modifiers on the mixture and concrete properties is carried out. The conditions of performing foundation structures in Rostov region are pointed out. The usage of rational methods of experimental planning the influence of micro silica compositions on the properties of concrete is investigated. The results of the calculations and statistical assessment of the obtained dependences allow predicting the strength of concrete in compression and, if it is necessary, adjusting the composition.
\end{abstract}

\section{Introduction}

In the 80 s of the last century the extra strong, quick- hardening modified concrete with low permeability, high corrosion resistance and durability is used in the construction industry of the world [1-2]. The structure of modifiers contains micro silica fume.

The research papers intended to improve the effective usage of micro silica (MS) (fumed silica, amorphous silica, micro silica) is carried out since middle of the last century [3-8]. Initially the usage of MS in concrete was explained by the problems of environmental protection. The first experience of using MS in concrete was done in 1971 at Fisko metallurgical plant in Norway [9]. In 1978 Norway government adopted a standard of using silica fume in concrete. In Canada, the usage of silica fume in concrete was approved in 1981, and then the procedure was done in other countries [3].

The popularity of using silica fume in concrete with high performance characteristics is not reduced until the present time [10]. In many developed foreign countries, the share of modified concrete used in construction industry is approximately equal to $100 \%$. In Russia, despite of the strong theoretical basis developed by domestic science in the field of concrete modification, the proportion of concrete with modifiers does not exceed $30 \%$ of the total volume of produced concrete [11].

A great number of finely dispersed dust loss is quite optimal for producing ferrosilicon (MS) obtained at Russian metallurgical plants but it is usually sent to the dump, while the UK annually imports more than 120,000 tons of silica fume for producing high-quality concrete in the country [10].

Despite the undeniable advantages of concrete with silica fume additions confirmed by numerous studies abroad and in this country [12-14], they do not widely applied in the

*Corresponding author: maslennikovsa@mail.ru 
construction industry of Rostov region. This fact is partly explained by the lack of accepted general design techniques of forming modified concrete due to the complex nature of the concrete mix components impact on the concrete characteristics. Therefore, the research aimed at studying the patterns of various factors impacts on the properties of modified concrete which is still relevant nowadays.

\section{Material and methods}

Analyzing the research papers concerning the modified concrete properties carried out in recent years, the researchers point out that the majority of these papers are intended to study the complex additives for obtaining concrete compositions with the highest performance characteristics. Moreover, high quality ballasts' for producing concrete were used in studies. Evaluating the effectiveness of using concrete additives is usually done by reducing the amount of cement in the composition mixture or by increasing the strength of the concrete. However, the price for MS is significantly higher than the cost of Portland cement, therefore, the usage of MS is hardly supposed to be profitable in the case [10].

However different types of the concrete with different design characteristics can be applied at various construction objects for different conditions. In case of using different modifiers sometimes a well known design technique can be hardly acceptable, as it has been proved by an ever increased number of laboratory tests. The process of using modifiers can influence the concrete price, so the customers and manufacturers of the concrete unwillingly try to use new compositions to reduce the costs.

In existed soil state the requirements to the concrete characteristics are significantly increased resulting in a significant increase in prices to concrete mixes as common compositions. This fact motivates customers and manufacturers of the concrete to use progressive methods to meet the modern requirements.

At present time the construction of different objects is being carried out in the town Shakhty. Most of engineering-geological segments located near the soil surface are characterized by sagged surface characteristics and by groundwater, though in some areas the depth of sulphate aggressive groundwater level does not exceed $1.0 \mathrm{~m}$. Besides there are some surface deformation processes connected with mining. These factors require to use special measures to improve sustaining capacity of foundation materials and complex structure foundations. Special requirements are known to be applied to the concrete

The department "Construction and Techno sphere safety" is carrying out comprehensive studies of the concrete properties with various additives for the construction companies. Paying attention to the requirements of customers concerning certain characteristics of the concrete the main task is supposed to minimize the price for the concrete materials. Therefore, taking into account the unique characteristics and multifunctional action of MS it is possible to increase frost resistance, abrasive strength, and resistance to various types of corrosion by means of increasing the concrete strength characteristics and reducing its permeability. It was proved at the first stage of the research experiment when the assessment of the impact of MS on the strength concrete characteristics was carried out.

The process of investigating the behavior of multi component systems is quite complicated task, so it is easier, to get dependences of the concrete strength on the amount of main components of the mixture. This procedure will determine the ingredients composition to obtain the desired strength of the concrete under a certain condition with given mobility of the mixture.

Since the concrete properties will depend mainly on three components (cement, water and MS additive), the dependency determined by means of conventional methods requires much time and a lot of materials. Therefore, in this case the most rational is to use methods of planning experimental procedure [15-16]. 
The most convenient, in our opinion, is a rational method of planning experiment process done by Brandon. The application of this method is explained by the fact that the experimental matrix has fewer test numbers than it may have when using other methods and the experimental results can be graphically expressed by means of sufficiently simple processing. And besides, the model is not built as a polynomial, but it is rather a product with autonomous functioning factors, ie. , having distinct physical meaning. The fact let the researchers describe complex types of dependencies of optimizing parameters on independent factors with sufficient accuracy at minimum period of time. At any range of variations it is possible to obtain the required factor space without using complex calculations. The model based on this method can be easily converted into different variables [15].

If the construction of the mathematical model is not required, it is necessary to determine the optimal ratio of components performing certain dependencies of concrete strength on the amount of ingredients and to select the desired ratio of them demonstrating them with the help of graphs.

The most simple implementation and calculation done by means of this method has a matrix number of variation levels which is equals to the number of factors. Consequently, it is necessary to plan the following levels $1.0+1$ for three independent factors.

Analyses of the concrete mixture, produced by different companies for construction purposes in the town Shakhty, let the researchers point out that the amount of cement needs is about 250 to $400 \mathrm{~kg}$, and water needs can be 160 to $230 \mathrm{~kg}$ per $1 \mathrm{~m} 3$ of mixture respectively. Paying attention to required need in minimizing spends on the concrete strength, water to produce the concrete mix, and the optimum amount of additive MS to reduce the high prices of the used materials, the following component variations are applied: cement 300, 330 and $360 \mathrm{~kg}$; MS 20, 30 and $40 \mathrm{~kg}$; water 190, 210 and $230 \mathrm{~kg}$ per $1 \mathrm{~m} 3$ of the mixture. The amount of ballast stones and sand is supposed to be the same as in case of producing the concrete of the designed class.

To prepare the samples the following ingredients were used, the cement M 500 made by Serebryakovsky plant, the sand was taken from Persiyanovskaya carrier with a module size of $1.61-1.67$, ballast stones fromSadkinskaya carrier with fractions of 10 - 20 having compressive strength 90 - $110 \mathrm{MPa}$..

The tests were conducted on samples with edges of $100 \mathrm{~mm}$ cube. There were 10 series of samples for nine compositions. For each of these nine compositions included in the experimental design, the slump and strength of samples for 1, 3, 7, 14 and 28 days the assessment of the concrete hardening process was performed. For every range with vibratory compaction 18 cubic meters were produced. Three or four samples were tested under control test terms.

According to the tests results private dependencies of the concrete strength on the amount of cement, the MS and the water in the concrete mixture were calculated and shown in Figure 1. 


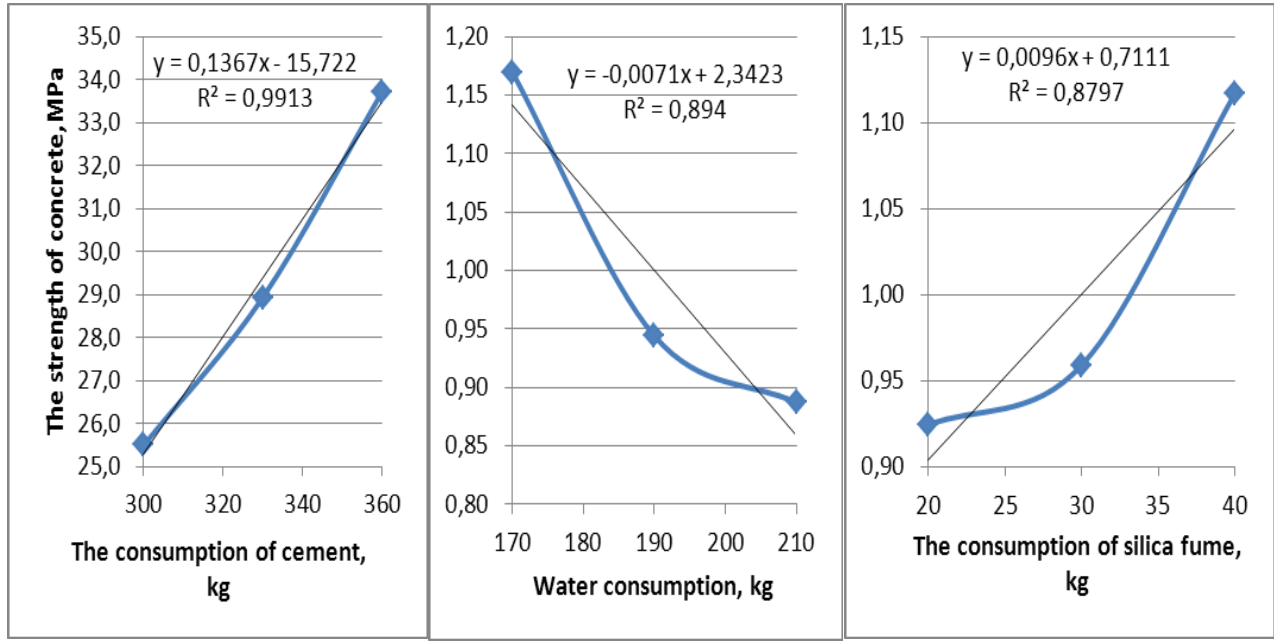

Fig. 1.The graph of dependencies of the concrete strength on the number of components in a mixture of $1 \mathrm{~m} 3$ after 28 days of the concrete hardening.

These dependencies are shown graphically to determine the composition of the intended design strength. According to the results of the statistical analysis [17] (Fig. 2) the mutual influence of independent factors on the strength of the concrete is pointed out.
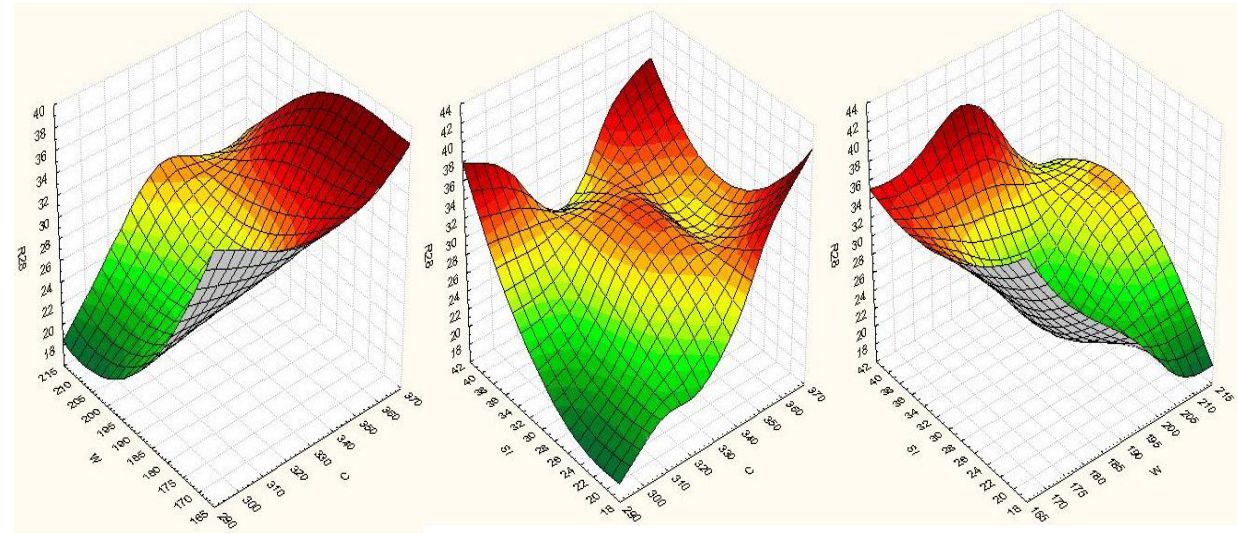

Fig. 2. The mutual influence of mixture components on the strength of concrete.

R28 - the concrete compressive strength after 28 days of hardening, C, W, Si -, respectively, the amount of cement, MS, and water per $1 \mathrm{~m} 3$ of the concrete mixture.

\section{Conclusion}

The results of processing the experiment plan the private dependencies of the concrete strength in the compression on the content of the ingredients are demonstrated, they can be justified by a sufficient degree of accuracy at all stages of the concrete hardening as they are supposed to be approximated by linear and polynomial functions. These facts resulted in the equations (1-3) to predict the concrete strength from 1, 3 and 28 days of hardening depending on the number of ingredients in the mixture. 


$$
\begin{aligned}
& R_{1}=(0,034 C-8,43)(-0,017 W+4.17)(0.012 S i+0.63) \\
& R_{3}=(0,123 C-27.1)(-0,014 W+3.59)(0.007 S i+0.80) \\
& R_{28}=(0,137 C-15.72)(-0,007 W+2.34)(0.01 S i+0.71)
\end{aligned}
$$

The performed study proves the optimal dosage of MS in the mixture which is equal to $8-11 \%$ of cement weight and improves the process of selecting the concrete composition. The received results are used for designing and adjusting the concrete composition by means of additives MS for producing piles and foundations.

\section{References}

1. I. M. Red,Concrete and reinforced concretem, 5, 10-11 (1987)

2. Yu. A.Minakov, O. V.Kononova, S. N.Anisimov, A. O.Smirnov, A. Yu.Leshkanov, Modern problems of science and education, 2-1 (2015)

3. P. Billberg, Self-Compacting Concrete for civil engineering structures the Swedish experience. Swedish Cement and Concrete Research Institute, Stockholm, 1999, CBI report 2:99, 80

4. M.Buil, H.Delage,Cement and Concrete Research, 17, 65-69 (1987)

5. Silica fume in Concrete, ACI Materials Journal, march-april (1987)

6. Silica Fume in Concrete. State of Art report, FIP, Thomas Telford Ltd (1988)

7. L.Hjorth, Microsilica in concrete (Aalborg Portland, Denmark, 1982)

8. L. Hjorth, Microsilica in Concrete (Aalborg Portland, Denmark, 1982)

9. M. V. Predtechensky,Influence of silica dust on forming of properties of high-strength concretehttp://build.rin.ru/articles/1598.html

10. A.G.Cat's, M. O.Korovkin, A.A.Urazova, N. A. Eroshkina,Modern scientific research and innovations, 12, (2014)

11. Efficiency of additives of microsilicon dioxide in case of http://stroyprofile.com/archive/1980 concrete modification.

12. H. Cheng-yi, R.F.Feldman, ACI Jornal, 740-743 (1985)

13. H. Cheng-yi, R.F. Feldman, Cement and Concrete Research, 15, 285-294 (1985)

14. L. Ya.Kramar, B. Ya.Trofimov, L. S.Mascot, F. M.Ivanov,Cement,6, 14-17 (1989)

15. A.I damask steels. Management of physical and chemical properties of grouting systems (Subsoil, Moscow, 1996)

16. L. S.Zazhigayev, A. A.Kishyan, Yu. I.Romanikov,Planning methods and handlings of results of a physical experiment (Atomizdat, Moscow, 1998)

17. E. N. Lviv, Statistical methods of creation of empirical formulas (Moscow, 1992) 